\title{
Study on The Change Law of Wave Velocity and Porosity of Triaxial Loaded Coal
}

donghui li ( $\square$ lidonghui@hpu.edu.cn )

Henan Polytechnic University

yanxia liang

Henan Polytechnic University

shiqiang chen

Henan Polytechnic University

kai zhang

Henan Polytechnic University

\section{Research}

Keywords: Triaxial loading, Wave velocity, stress-strain, porosity, Mechanical properties

Posted Date: April 28th, 2020

DOl: https://doi.org/10.21203/rs.3.rs-23575/v1

License: @ (i) This work is licensed under a Creative Commons Attribution 4.0 International License. Read Full License 


\title{
Study on The Change Law of Wave Velocity and Porosity of Triaxial Loaded Coal
}

\author{
Donghui Li ${ }^{1,2}$ Yanxia Liang ${ }^{1}$ ShiQiang Chen ${ }^{1}$ Kai Zhang ${ }^{1}$ \\ 1. State Key Laboratory Cultivation Base for Gas Geology and Gas Control, Henan Polytechnic University, Henan \\ Province, 454000,China; \\ 2. Collaborative Innovation Center of Central Plains Economic Region for Coalbed /Shale Gas, Henan Province, \\ 454000, China;
}

Abstract: The mechanical properties of loaded coal time to time, so that the voice wave propagation in coal changes with it. In order to study the relationship between the wave velocity of coal and its mechanical properties.The ultrasonic testing system was used to calculate the wave velocity of loaded coal at different times through laboratory triaxial loading test.The relationship between the wave velocity of loaded coal-body and the confining pressure of different coaxial pressures was analyzed.The results show that the wave velocity is positively correlated with the axial pressure under the same confining pressure. By calculating the variation of wave velocity of different loaded coal bodies. it is concluded that the variation of wave velocity of coal bodies can reflect the mechanical state of coal bodies undergo the compaction stage, the elastic stage and the new stage of crevasse. At the same time, the change of wave velocity in coal is affected by the porosity of the pressure-bearing coal-boby. Porosity was calculated using stress-strain.It was found that porosity and axial pressure presented a good negative correlation under the same confining pressure, and the change in wave velocity is exactly right opposite to the porosity change trend diagram.It can be obtained that the larger the amplitude of wave velocity change is, the smaller the porosity change is, and the smaller the amplitude of wave velocity change is, the larger the porosity change of coal body is, which is consistent with the actual analysis. It verifies the different the pressure-bearing coal-boby change in wave velocity to the feasibility of analyzing the mechanical condition of the loaded coal body. making the analysis more persuasive. It provides basis for coal body bearing and safe mining.

Keywords: Triaxial loading、Wave velocity、stress-strain、porosity、Mechanical properties

0 Introduction

Coal and rock mass will produce a large number of pores and cracks under the actions of ground stress and tectonic stress. These pores and cracks become carriers in gas storage. They are also the root cause of coal and gas outburst accidents. Therefore, the understanding of pores and cracks is conducive to the prevention of geological disasters. The ultrasonic parameters of coal mass could reflect coal structures and mechanical and physical properties. They have close relationships with coal density [1] and are the basis of seismic and geophysical exploration. The pores and cracks could affect the elastic wave propagation. In the 1940s, Bom studied the attenuation constants of earth materials, opened up the field of the attenuation of elastic waves [2] and started the application of elastic waves in coal and rock mass. In 1966, Walsh [3-4] conducted the ultrasonic test on rocks. The results showed that the fracture closure and expansion in rocks could impact the velocity of acoustic waves as well as mechanical properties of rocks. However, the testing was carried out at constant temperature and pressure that was not in accord with the actual ground stress. Tiedemann [5], Zhai [6], Zhao [7], Zhao [8] et al. studied the coal and rock mass under uniaxial loading. They obtained that the higher the coal density, the faster the acoustic wave propagation and the slower the attenuation. Considering the complex real ground stresses, scholars studied the mechanical properties and pores of coal mass under triaxial compression. T.P.Medhurst and E.T.Brown [9], Zhang [10], Zhao and Hao [11] et al. studied the coal mass under the conventional triaxial compression. The results indicated that the wave velocity variation had good relationships with mechanical properties of coal mass and the distribution of pores and fractures in coal mass. The P wave velocity was the largest along the direction of the fractures, and the minimum velocity was in the direction of the vertical fractures. Zhang, Zhao and Zhou et al. [12-14] studied coal mass under uniaxial compression and triaxial compression. The results showed that pores and fractures had obvious influences on anisotropy and the wave velocity.

To sum up, domestic and foreign scholars have conducted a large number of studies on the influence of rock porosity on the physical characteristics of coal body, and reached a series of conclusions. However, few studies have been conducted on the porosity of coal seam, and the use of wave velocity change and porosity change to analyze the stress state of coal body is even less. The pores and fractures were changing due to the changing coal stress during the mining. The wave velocity varied with the changes of pores and fractures, so the analyses of wave velocity variations could clearly get the degree of pores and fractures changes of coal mass under 
mining-induced stresses. Therefore, In this paper, the mechanics experiment of coal body under triaxial loading in the laboratory was carried out. The relationship between wave velocity and porosity is analyzed by calculating wave velocity of loaded coal with wave meter and calculating porosity with stress-strain. The wave velocity variation is used to analyze the stress state of the coal body. Meanwhile, the porosity variation is used to verify the feasibility of the wave velocity variation to analyze the stress state of the coal body, making the analysis more persuasive. The experimental results show that the relationship between wave velocity and porosity can be used to understand the structural mechanical properties of coal seams, such as bedding and pore cracks, and therefore this research may has a good application prospect.

\section{The coal ultrasonic velocity and stress-strain experiment}

\subsection{Principles of the experiment}

The ultrasonic wave is a mechanical vibration wave in the elastic medium. Its propagation depends on the fluctuations caused by the elastic deformation of particles, and has a direct relationship with fractures inside the coal mass. With better coal structures, larger coal density, less pores and faster wave velocity, there are less energy loss and longer propagation distance, as well well more complete interior structures.

\subsection{The experiment equipment}

The coal reservoir fracturing simulation and physical characteristic testing system self-developed by State Key Laboratory Cultivation Base for Gas Geology and Gas Control, Henan Polytechnic University was adopted in the triaxial loaded ultrasonic testing system, as shown in figure 1-1.

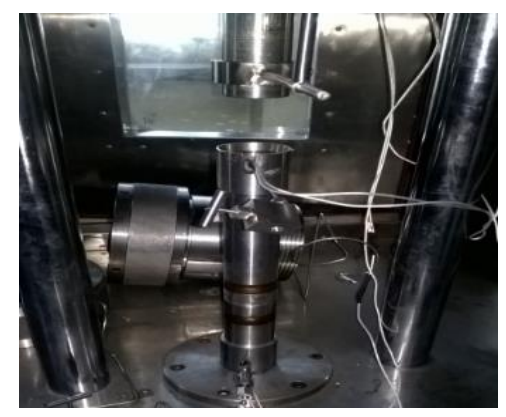

Fig.1-1Coal reservoir fracturing simulation and physical properties of the test system

(2) The stress-strain testing equipment

The stress-strain system consists of Donghua DH3821 static strain testing system, strain gauge and channel connection, as shown in figure 1-2. The DH3821 static strain testing system is small sized and convenient with self-checking functions. The continuous sampling rate of each measuring point was $2 \mathrm{~Hz}$. The full-scale value of strain was $\pm 20000 \mu \varepsilon$. The resolution was $1 \mu \varepsilon$. The indication error of the system was no more than $0.5 \% \pm 3 \mu$. The type of the strain gauge was BAM350-5AA-G200. The size of the sensitive grid was $5.0 \mathrm{~mm} \times 2.9 \mathrm{~mm}$, and the base size was $9.3 \mathrm{~mm} \times 4.5 \mathrm{~mm}$.

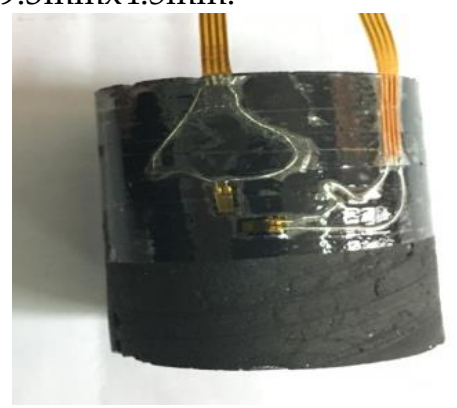

Fig.1-2 Test component diagram of stress and strain of coal body

\subsection{The experimental scheme}

This experiment studied the raw coal in the 15091 working face in No.2-1 coal seam in Shanxi Formation in Guhanshan Coal Mine in Jiaozuo. The depth of the selected coal sample was between $350 \mathrm{~m}$ and $400 \mathrm{~m}$. The confining pressure of the coal sample was between $1 \mathrm{MPa}$ and $6 \mathrm{MPa}$, and the axial pressure was between $5 \mathrm{MPa}$ and $13 \mathrm{MPa}$. The confining pressures of $1 \mathrm{MPa}, 3 \mathrm{MPa}$ and $5 \mathrm{MPa}$, and the axial pressure increase of 
$1 \mathrm{MPa}$ each time were chosen in the laboratory to accord better with the actual ground stress. The sampling was carried out in strict accordance with relevant national standards. Firstly, the fresh bulk coal was exploited and immediately taped tightly to ensure the sealing effect. Secondly, the coal body was transported to the ground as soon as possible and sealed again through wax infiltration. According to the measuring results, the drilling of cores was planned properly through drawing and recording the dividing chalk lines clearly and cutting the coal by the cutting machine. The safety must be ensured during the operation of the cutting machine. The coal should be cut stably and smoothly. To guarantee the sample stability during the processing, a flat section was necessary. Figure 1-3 shows the coal sample after drilling. The sample preparation took the direction parallel to face cleat as the $\mathrm{x}$-axis, the direction parallel to bull cleat as the $y$-axis and the direction vertical to the bedding as the $z$-axis. The coal sample was processed into cylinder samples with the diameter of $50 \mathrm{~mm}$ and the height of $100 \mathrm{~mm}$. The dry samples were obtained after using an oven for $24 \mathrm{~h}$. Then they were divided into three groups ( 3 in each group parallel to $\mathrm{x}$-axis, $\mathrm{y}$-axis and $\mathrm{z}$-axis) and loaded with various confining pressures and axis pressures. At the same time, the strain gages were used to coal pillars, and coal samples were loaded by confining pressures and axis pressures in press. With confining pressures of $1 \mathrm{MPa}, 3 \mathrm{MPa}$ and $5 \mathrm{MPa}$, and the axial pressures of $0 \mathrm{MPa}, 1 \mathrm{MPa}, 2 \mathrm{MPa} \ldots \ldots .11 \mathrm{MPa}$, the ultrasonic testing and stress-strain testing were conducted. In the experiment, the confining pressure was the same, and the axial pressure increased from low to high with each increment of $1 \mathrm{MPa}$. The rate of loading was $0.5 \mathrm{MPa} / \mathrm{min}$. After the each loaded axial pressure became stable, the pressure holding time was $20 \mathrm{~min}$.
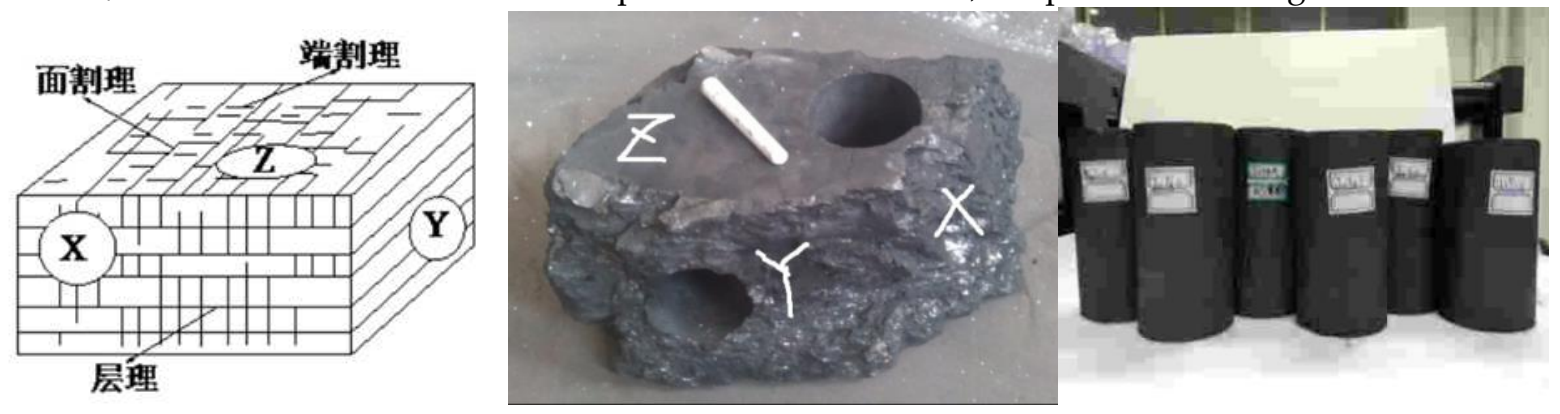

Fig.1-3 Coal cleat system and coal sample after drilling

\section{Experimental results and analyses}

\subsection{Wave velocity variation calculation and analysis}

The following formula could be used to calculate $V_{p}$.

$$
V_{p}=L / t_{p}-t_{0}
$$

Where $V_{p}$-velocity of the longitudinal wave $(\mathrm{m} / \mathrm{s})$;

$L$ - distance between upper or lower plug and the center of the transducer (m);

$t_{p}$ - Traveling time of a longitudinal wave in the sample (s);

$t_{s}$ - Traveling time of a shear wave in the sample (s);

to -zero delay of the instrument system (s).

When the coal mass was under loading and wasn't be crushed, the increase of axial pressures resulted in the reduction in coal length and the continuous increase in wave velocity. However, the changing states of the loaded coal couldn't be reflected. According to the experimental scheme in this paper, the coal changes after each loading were at steady state, and each change occurred on the basis of the last change. Therefore, the analyses of velocity changes at each stage were conducive to the understanding of coal variation degree and fracturing degree. The velocity difference analysis of waves was conducted, as follows:

$$
\triangle V=V P i-V_{p(i-1)}
$$


Where $\Delta V$ - the variation of the velocity of longitudinal wave $i$ - the amount of the loaded axial pressure

$V_{\mathrm{Pi}}$ - the velocity of the longitudinal wave under loading of the axial pressure.

Based on the data measured by the experimental equipment and by formula (2-1), figure $\mathrm{a}, \mathrm{d}$ and $\mathrm{g}$ show the wave velocities at the confining pressures of $1 \mathrm{MPa}, 3 \mathrm{MPa}$ and $5 \mathrm{MPa}$ and the changing axial pressures. Through experimental data, the confining pressures were $1 \mathrm{MPa}, 3 \mathrm{MPa}$ and $5 \mathrm{MPa}$, and the axial pressures were the ultrasonic wave velocities (parallel to face cleat $\mathrm{x}$-axial, parallel to bull cleat $\mathrm{y}$-axis and vertical to bedding $\mathrm{z}$-axis) of $0 \mathrm{MPa}, 1 \mathrm{MPa}, 2 \mathrm{MPa} \ldots . . .11 \mathrm{MPa}$, the confining pressures were $1 \mathrm{MPa}, 3 \mathrm{MPa}$ and $5 \mathrm{MPa}$, respectively by formula (2-2), as shown in figure $c$, $f$ and $i$.

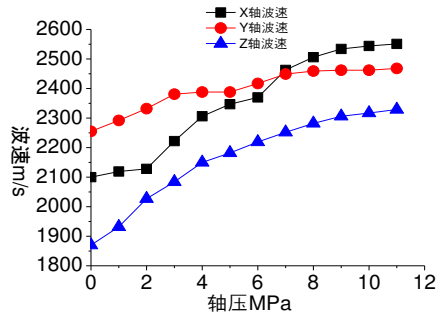

a Wave figure

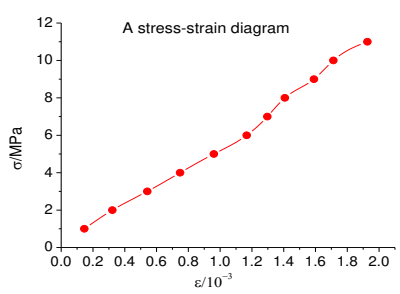

b A stress-strain diagram

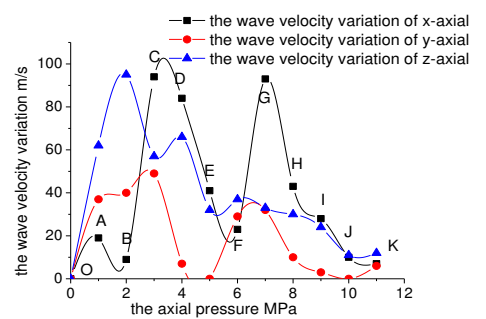

c Wave velocity change chart

Fig. 2-1 Wave velocity, stress-strain curves and wave velocity variations at $\mathrm{X}, \mathrm{Y}$ and $\mathrm{Z}$ axes at $1 \mathrm{Mpa}$ confining pressure

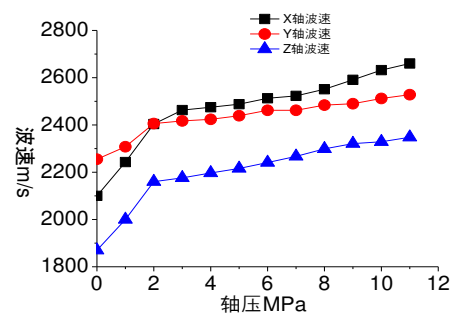

d Wave figure

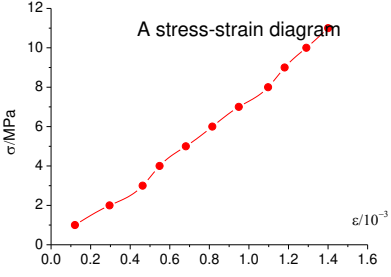

e A stress-strain diagram

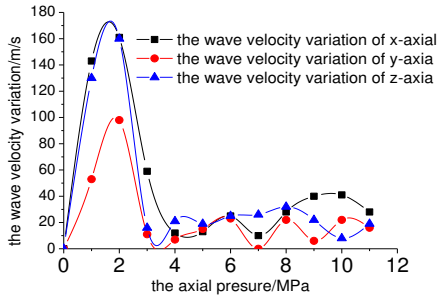

f Wave velocity change chart

Fig.2-2 Wave velocity, stress-strain curves and wave velocity variations at $\mathrm{X}, \mathrm{Y}$ and $\mathrm{Z}$ axes at $1 \mathrm{MPa}$ confining pressure

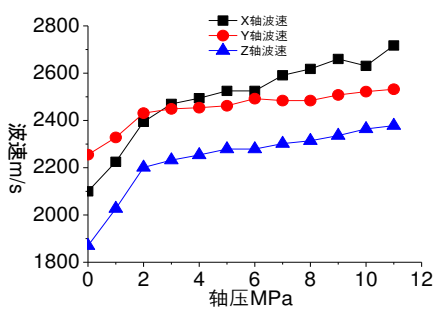

g Wave figure
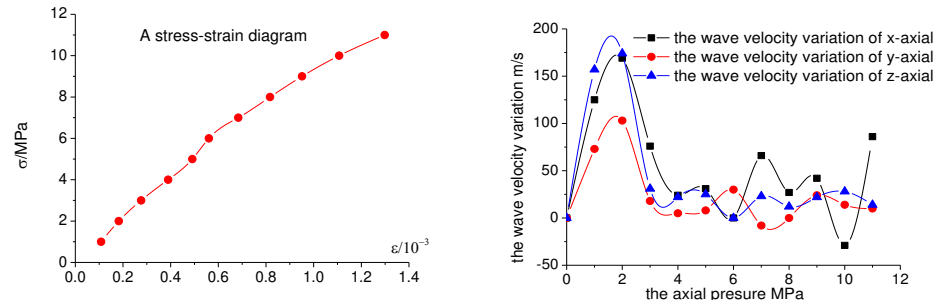

h A stress-strain diag

i Wave velocity change chart

Fig. 2-3 Wave velocity, stress-strain curves and wave velocity variation at $\mathrm{X}, \mathrm{Y}$ and $\mathrm{Z}$ axes at the confining of $1 \mathrm{MPa}$

The wave velocity diagrams showed that the wave velocity of the loaded coal increased constantly without downward trend or zero trend, presenting that the loaded coal wasn't completely damaged. If the coal was damaged completely, the wave velocity couldn't be measured. The curves were rising and they didn't appear to peak, indicating that the coal mass wasn't completely damaged. Although the coal structure was changed, it was compacted. New fractures occurred as the axial pressure increased.

The analysis was carried out at the confining pressure of 1Mpa. As shown in figure 2-1c, the wave velocity in $\mathrm{OA}$ and $\mathrm{OB}$ bands changed slowly. It was indicated that when the confining pressure was the same and the axial pressure changed from $0 \mathrm{MPa}$ into $1 \mathrm{MPa}$ and $2 \mathrm{MPa}$, the coal sample and the pores in sample were compacted. The degree of the compaction was not high and the increase in wave velocity variation was not obvious. The coal sample was still in the stage of preliminary compaction. In BC bands, the axial pressure was $3 \mathrm{MPa}$, and the wave velocity variation reached $94 \mathrm{~m} / \mathrm{s}$, which was much larger than that in 
$\mathrm{AB}$ bands. At this point, the degree of the coal sample compaction was high. The pores and fractures had small development degree. The increment of wave velocity nearly reached the maximum. The coal was in the stage of elastic stage. In CD bands, the axial pressure was $4 \mathrm{MPa}$, and the wave velocity variation was $84 \mathrm{~m} / \mathrm{s}$. The increment in this stage was not bigger than that in $\mathrm{BC}$ bands, indicating that the coal sample compaction degree was still large and was not larger than that in BC bands. At this time, due to new fractures, the wave velocity increment declined. The coal sample was not in the elastic stage. The increasing axial pressure led to resistance to deformation of coal sample, causing relatively small velocity difference decline. The coal was in the yield stage. In DE bands, the axial pressure was $5 \mathrm{MPa}$ and the wave velocity variation was $41 \mathrm{~m} / \mathrm{s}$. The wave velocity variation declined fast, indicating that pores and fractures had high degree of development. The new fractures due to the increasing axial pressure reduced the increment of the wave velocity. At this time, the coal sample was in the stage of fracture expansion or regeneration. The decline of the velocity from $94 \mathrm{~m} / \mathrm{s}$ to $41 \mathrm{~m} / \mathrm{s}$ showed that the microfissures of the loaded coal had great influences on wave velocity variation. In EF bands, the wave velocity was still decreasing. It could be seen that with the increase of the axial pressure, new fractures increased continuously. The degree of damage also increased, and the coal sample was not completely damaged.

Due to the confining pressure, the coal sample wasn't completely damaged under axial compression to a certain degree. In figure 2-1, the stages of FG, GH, HI, IJ and IK formed a cycle phase of OA, AB, BC, CD, $\mathrm{DE}$ and $\mathrm{EF}$. In the phase of $\mathrm{JK}$, the axial pressure was large and the fractures were abundant. The axial pressure increase exceeding certain limit would cause complete damage of the coal sample, and the wave velocity would not increase. The velocity change in the latter cycle was smaller than that in the last cycle. It was illustrated that the coal sample formed an elastic body after compaction in the former cycle. With the increasing axial compression, the elastic coal mass had resistance to deformation. As shown in figure 2-1, at a confining pressure of $1 \mathrm{MPa}$ at $\mathrm{x}$-axis and $\mathrm{y}$-axis, the degree of coal compaction was the best when the axial pressure was $3 \mathrm{MPa}$. The degree of compaction was fast at $\mathrm{z}$-axis vertical to the bedding plane. When the axial pressure was $2 \mathrm{MPa}$, the compaction degree was the best.

Similarly, when the confining pressures were $3 \mathrm{MPa}$ and $5 \mathrm{MPa}$, the coal sample experienced the initial compaction stage, elastic stage, yield stage, fracture expansion or regeneration stage with the changing axial pressures. Figure 2-1, 2-2 and 2-3 showed that as the confining pressure increased during the loading process, the wave velocity variation increased constantly in the first cycle phase. This was because the increase in the confining pressure led to more cracks, and the coal was changed greatly as the axial pressure increased. With the increasing confining pressure, the four stages of the coal sample jumped ahead. The elastic stage advanced to $2 \mathrm{MPa}$ rather than $3 \mathrm{MPa}$ at the confining pressure of $1 \mathrm{MPa}$. In addition, the damage resistance of the coal was enhanced as the confining pressure increased. Thus, new fractures were not likely to occur. That's why the wave velocity variations became relatively small with the increasing axial pressure after the first cycle stage.

\subsection{Calculation and analysis of porosity variations}

I. Derivation of the porosity model of the coal

The expansion and closure of the fractures could be observed under the loading of the coal, and consequently changed ultrasound parameters. The changes of the fractures were the bridge to the establishment of the relationship between the stress and ultrasonic waves. Under the actions of the stresses, the cracks were changed from the microscopic point of view, and the porosity occurred changes from a macro perspective. According to the definition of the strain, the strain in fracture volume was affected by the changes of fracture size, and finally, the total volume of the coal was changed. According to the relationship 
between the porosity and the strain, the volume of the porosity and fracture after the deformation was equal to the volume before the deformation minus the total deformation amount and temperature expansion amount of the coal. Therefore, the relationship between the porosity and the strain could be expressed as follows:

$$
\begin{aligned}
& \varphi=\frac{V_{P}}{V_{T}}=\frac{V_{P 0}+\Delta V_{P}}{V_{T 0}+\Delta V_{T}} \\
& =1-\frac{V_{S 0}\left(1+\Delta V_{S} / V_{S 0}\right)}{V_{T 0}\left(1+\Delta V_{T} / V_{T 0}\right)} \\
& =1-\frac{\frac{V_{T 0}-V_{P 0}}{V_{T 0}}}{1+\frac{\Delta V_{T}}{V_{T 0}}}\left(1+\frac{\Delta V_{S}}{V_{S 0}}\right) \\
& =1-\frac{1-\varphi_{0}}{1+\varepsilon_{V}}\left(1+\frac{\Delta V_{S}}{V_{S 0}}\right)
\end{aligned}
$$

Where VT - the total volume of the coal; VP - the volume of the coal; $\Delta \mathrm{VS}$-volume change of the coal skeleton; VS - the volume of the coal skeleton; $\Delta \mathrm{VP}-$ volume changes of the coal; $\Delta \mathrm{V}_{\mathrm{T} 0}$ - the initial total volume of the coal; $\Delta \mathrm{VT}_{\mathrm{T}}-$ volume changes of the coal; $\Delta \mathrm{V}_{\mathrm{s} 0}$ - the initial volume of the coal skeleton; $\Delta \mathrm{VP}_{\mathrm{P} 0}-$ the initial volume of the coal; $\varphi$ - the porosity; $\varphi_{0}-$ the original porosity of the coal.

II. The relation equation of porosity and strain under the influence of temperature

Formula (3-4) indicated that the change of the coal porosity was determined by the initial porosity $\varphi_{0}$, the volume strain $\varepsilon v$ and strain increment. Under the actions of the triaxial stress, $\Delta V S$ only considered the variations of temperature effect $\Delta \mathrm{VST}$. The strain increment could be expressed as follows:

$$
\frac{\Delta V_{S}}{V_{S 0}}=\frac{\Delta V_{S T}}{V_{S 0}}=\varepsilon_{f}
$$

The porosity could be expressed as follows:

$$
\varphi=1-\frac{1-\varphi_{0}}{1+\varepsilon_{V}}\left(1+\varepsilon_{f}\right)
$$

The deformation amount of the thermal expansion could be expressed as follows:

$$
\varepsilon_{f}= \pm \beta \Delta T
$$

Where $\Delta \mathrm{T}$ is the variation (T-T0) of the absolute temperature; $\beta$ is the volumetric thermal expansion coefficient of the coal. The simultaneous equation of (3-6) and (3-7) was expressed, as follows:

$$
\varphi=1-\frac{1-\varphi_{0}}{1+\varepsilon_{V}}\left[1 \pm \beta\left(T-T_{0}\right)\right]
$$

At the normal temperature, only the ultrasonic-strain experiment was carried out under the triaxial loading of the coal. Therefore, the porosity model was simplified. The influences of the temperature on the porosity were ignored, and only the porosity was considered. Figures k, m and o show the porosity variations by formula (3-8).
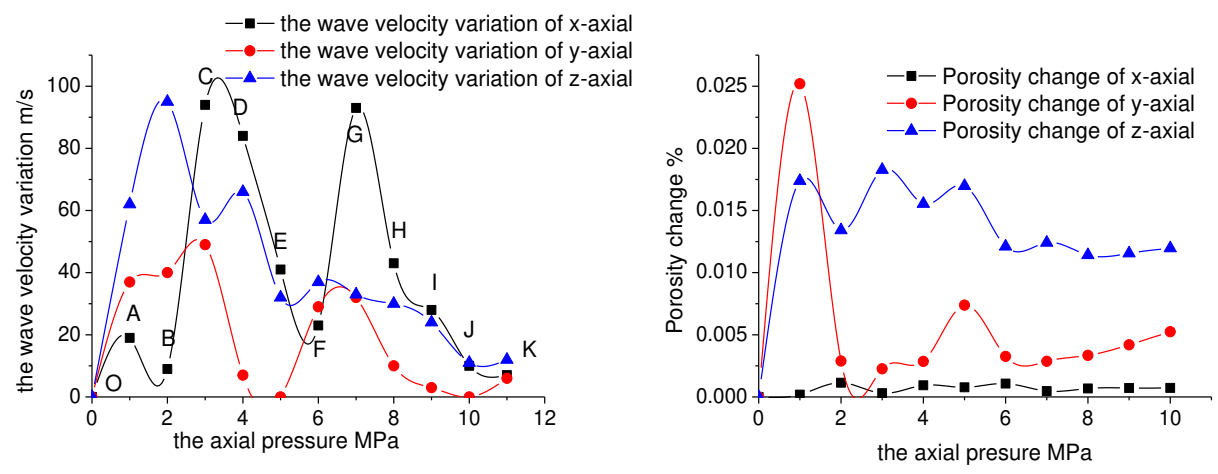
g Wave velocity change chart

k Porosity change chart

Fig. 3-1 Wave velocity change and pore change at the confining pressure of $1 \mathrm{MPa}$

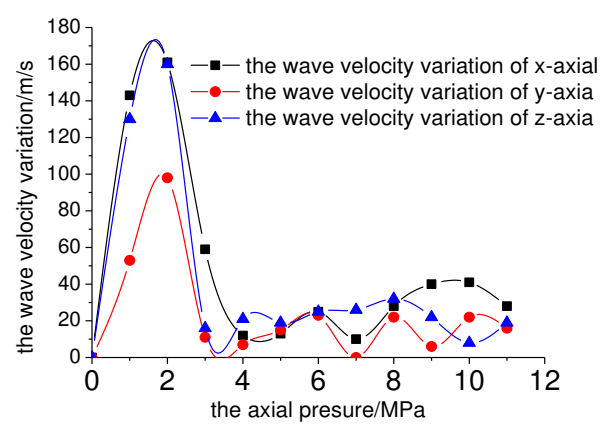

1 Wave velocity change chart

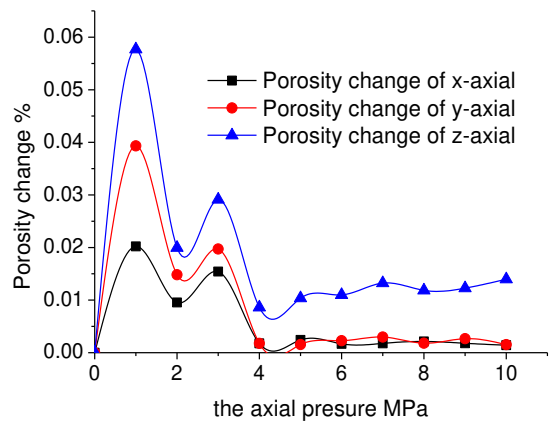

$\mathrm{m}$ Porosity change chart

Fig. 3-2 Wave velocity change and pore change at the confining pressure of $3 \mathrm{MPa}$

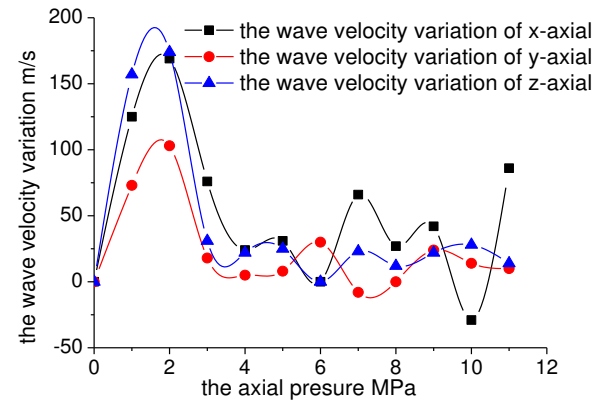

n Wave velocity change chart

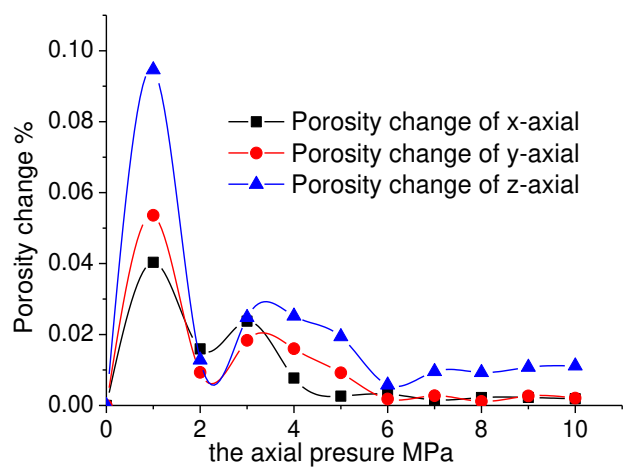

o Porosity change chart

Fig. 3-3 Wave velocity change and pore change at the confining pressure of $5 \mathrm{MPa}$ 
During the analyses of the wave velocity variations, the states of the loaded coal were divided into the initial compaction stage, the elastic stage, yield stage and fracture expansion or regeneration stage. The analyses of figures 3-1, 3-2 and 3-3 indicated that the wave velocity propagated fast and changed greatly. This was because the pores in coal were compacted at the initial compaction stage, and the corresponding porosity variations were large in the finger. The fractures were not abundant at $x$-axis (the direction parallel to face cleat) and $y$-axis (the direction parallel to bull cleat). Fractures were common at z-axis (the direction vertical to the bedding), followed by $y$-axis and $x$-axis. The biggest porosity variations was at z-axis at the compaction

stage. At the elastic stage, the coal had the highest degree of compaction, the largest wave velocity variation and the least porosity variation. This was because porosity variations became small at this stage. The large pore variation could lead to rich pores and thus reduce the wave velocity of propagation and variations. After experiencing the elastic stage, the coal was compacted and regarded as an elastic body. The coal had a certain resistance with the increasing pressure. Although new fractures occurred at the yield stage and the fracture expansion or regeneration stage, the amplitude of pore variations was relatively small and thus the amplitude of the wave velocity variation also became small. The wave velocity variation was great at the confining pressure of $1 \mathrm{MPa}$. This was because the confining pressure and the coal's anti-pressure ability were small, and pores and fractures in coal developed obviously with the increase of the axial pressure. The compression strength of the coal increased with the increasing confining pressure. The continuous increase in the axial pressure made the pores and fractures develop slowly, and the amplitude change of pore variations was reduced. It always followed the law that the wave velocity variations were large and the pore variations were small, and vice versa.

\section{The coupling analysis of wave velocity and porosity variation}

The analysis of wave velocity variations could reflect the compaction degree of coal and pore changes. The variations of wave velocity could reflect the variation degree of pores. The large wave velocity variation illustrated that variations of coal pores were relatively small and the wave travelled fast, and vice versa. The change law of wave velocity variation and the porosity variation was analyzed at the confining pressure of 3Mpa (figure 3-2). At the compaction stage under the axial pressure of $1 \mathrm{MPa}$, the coal was compacted. The wave velocity variation was large, and the largest porosity variation occurred at z-axis. This was because $x$-axis was in parallel to face cleat, and $y$-axis was in parallel to bull cleat. The development degrees of fractures were relatively low at $\mathrm{x}$-axis and $\mathrm{y}$-axis with porosity variations of $0.0202 \%$ and $0.0393 \%$, respectively. While the fractures were abundant at $\mathrm{z}$-axis in parallel to bedding with the largest porosity variation of $0.0577 \%$. At the elastic stage under the axial pressure of $2 \mathrm{MPa}$, the coal was further compacted. The wave velocity varied fast. At this time, the porosity variation was the smallest. The small pore changes at this stage caused fast wave propagation velocity and thus the wave velocity variation was the largest. At this point, the porosity variations at $\mathrm{x}$-axis, $\mathrm{y}$-axis and $\mathrm{z}$-axis were $0.0096 \%, 0.0148 \%$ and $0.0200 \%$, respectively. At the yield stage under the axial pressure of $3 \mathrm{MPa}$, the loaded coal was damaged and cracks increased. The wave velocity variation reduced and the coal pore 
changes increased. At the fracture expansion or regeneration stage, coal had a certain of resistance ability after experiencing the elastic stage and yield stage. The continuous pressure was not easy to destroy the coal, so the amplitude of pore changes at this stage was relatively small. After reaching the axial pressure of $5 \mathrm{MPa}$, the amplitude of wave velocity variations decreased, and the initial compaction stage, elastic stage, yield stage and fracture expansion or regeneration stage still reappeared. At the same time, the porosity variation amplitude showed sharp drop. In particular, the greater the confining pressure, the smaller the amplitude variation in the later cycle stage. The coupling analysis of wave velocity variations and porosity variations showed that, except for the compaction stage, the greater the wave velocity variation, the smaller the coal porosity, and vice versa.

\section{Conclusions}

In this paper, the ultrasonic velocity test of the coal was firstly carried out under the triaxial loading. Then wave velocity variations and porosity changes were calculated. The relationships among mechanical changes of coal pores and fractures development, wave velocity variations and porosity variations were analyzed. The conclusions were as follows:

I. Pores and fractures produced by the loaded coal had significant effects on acoustic waves. At the confining pressure of $1 \mathrm{MPa}$, the coal's degree of compaction was high, and the development degree of pores and fractures was low at the elastic stage. The wave velocity variation was $94 \mathrm{~m} / \mathrm{s}$. After reaching the fracture expansion or regeneration stage, the development degree of pores and fractures became high, and the wave velocity variation reduced to $41 \mathrm{~m} / \mathrm{s}$. The larger the confining pressure, the more obviously the wave velocity varied from the elastic stage to the fracture expansion or regeneration stage. At the confining pressure of $3 \mathrm{MPa}$, the wave velocity variation changed from $161 \mathrm{~m} / \mathrm{s}$ to $59 \mathrm{~m} / \mathrm{s}$. At the confining pressure of $5 \mathrm{MPa}$, the wave velocity variation changed from $169 \mathrm{~m} / \mathrm{s}$ to $76 \mathrm{~m} / \mathrm{s}$.

II. The wave velocity diagram indicated that the coal was anisotropic due to different triaxial wave velocities. During the loading process, the amplitudes of wave velocity variations were changing, proving that the coal was experiencing various stages, that is the initial compaction stage, the elastic stage, the yield stage and fracture expansion or regeneration stage. The cyclic change of the wave velocity differences showed that these four stages tended to reappear within certain range of axial pressure. As the confining pressure increased, wave velocity variations continued to increase in the first phase of the cycle. This was because the increase in the confining pressure caused more fractures and the coal was changed greatly under the actions of the axial pressure. The further increase of the confining pressure would enhance the damage resistance of coal. Therefore, the amplitude of the wave velocity variations was relatively small after the first cycle phase.

III. The coal pores and fractures could directly impact wave velocity variations. At the compaction stage, the pores and fracture variation reached $0.14 \%$, and the wave velocity variation was obvious and reached $94 \mathrm{~m} / \mathrm{s}$. The greater the confining pressure, the more obvious the change was. The confining pressure had significant influences on fractures of the loaded coal.

IV. The coupling analysis results of the wave velocity differences and the porosity variations indicated that the larger the amplitude of the wave velocity variation, the smaller the coal 
porosity variations, and vice versa. As the confining pressure continued to increase, the damage resistance of coal was enhanced and new fractures were not likely to form. At this time, the amplitude of porosity variations also became small.

Author Contributions: All authors have worked on this manuscript together and all authors have read and approved the final manuscript.

Funding: This research was funded in part by the National Natural Science Foundation of China(Grant No.U1704129);in part by the Natural Science Foundation of Henan Province in China (Grant

No.182300410138); in part by the Post_doctoral Research Fund of Henan Province in China (Grant No.19030070).

Conflicts of Interest: The authors declare no conflict of interest

\section{References}

1.Zhang. C.Y, Wan. W. K, Wang. S. Sun. X.L et al. Conversion method from ultrasonic to seismic velocity based on rock integrity assessment [J]. Chinese Journal of Rock Mechanics and Engineering, 2018, (06) :1-2.

2. Born T. The attenuation constant of earth materials[J]. Geophysics.2002,(6):65-73.

3. Walsh J B, Brace W F.Elasticity of rock: A review of some recent theoretical studies [J].Rock mechEng Geol. 1966,( 4):283-296.

4. Walsh J B. Brace W F. Cracks and pores in rocks Int [J]. Congress on rock mech.Lisbon.1966:(3):641-643.

5. Meng. Z. P, Zhang. J. C. Joachim Tiedemann. Relationship between physical and mechanical parameters and acoustic wave velocity of coal measure rocks [J]. Chinese J. Geophys. (in Chinese), 2006.

6. Zhai. X. J. The experimental research of ultrasonic characterization for rock under uniaxial load [D]. Chengdu University of Technology, 2008 ,(06): 42-50.

7. Zhao. M. J. Analysis of influence of earthquake longitudinal wave on tower structure. Journal of Chongqing Jiaotong institute, 2000, (06) :79-82.

8. Zhao Y. An experimental study of ultrasonic anisotropy of coal under uniaxial loading [J]. Geophysical \& Geochemical Exploration, 2017, (04): 306-309.

9. Medhurst T P, Brown E T, Medhurst T P, et al. A study of the mechanical behaviour of coal for pillar design[J]. International Journal of Rock Mechanics \& Mining Sciences. 1998, 35(98): 1087-1105.

10. Zhang. Y. et al. Different lithologies coal and rock under the triaxial compression strength and deformation characteristics. Journal of Xi' an University of science and technology, 2015, (11):709-713.

11.Zhao. Q. Hao. S. L. Anisotropy test instance of ultrasonic velocity and attenuation of coal sample [J]. Process in Geophysics, 2006.21(06): 532-534.

12.Zhang. Y., Zhang. Y. G., Zhang. Y. G., Zhou. J. Y. et al. An experimental study of ultrasonic anisotropy of coal under uniaxial loading [J]. Geophysical \& Geochemical Exploration, 2017, (2): 306-310.

13.Zhao. Y., Zhang. Y. G., Yu. H. Y. Experimental research on effects of water absorption on acoustic velocity anisotropy in coal rock [J]. Oil Geophysical Prospecting. 2017 (5): 999-1004.

14. Zhang. Y., Zhang. Y. G., Wang. S. L. Experimental study on ultrasonic anisotropic characteristics of Nitrogen-containing coal bodies [J]. Journal of Southwest Petroleum University (Science \& Technology Edition). 2018, 40(2):83-90. 
Figures
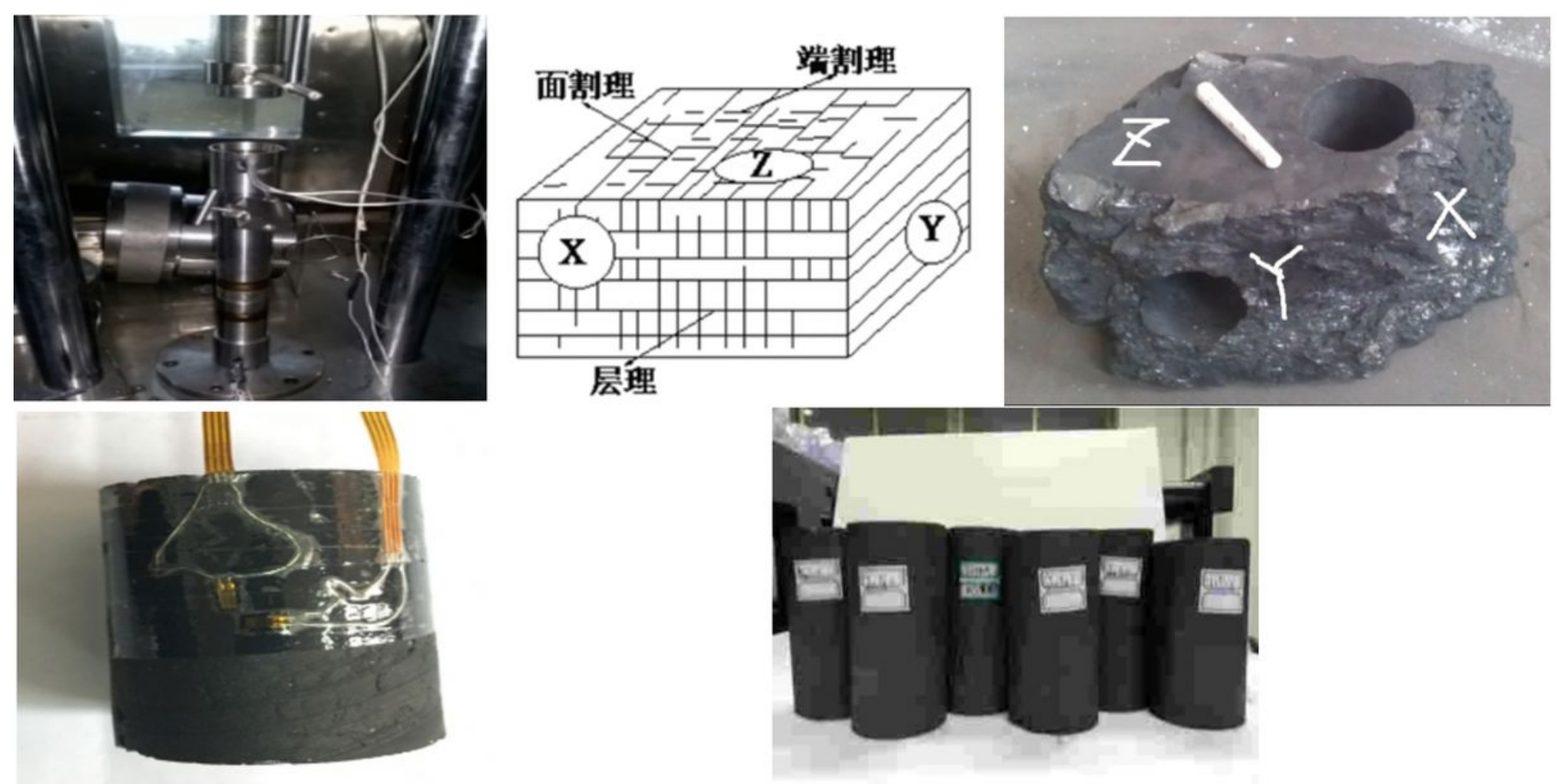

Figure 1

1-1Coal reservoir fracturing simulation and physical properties of the test system. 1-2 Test component diagram of stress and strain of coal body. 1-3 Coal cleat system and coal sample after drilling 

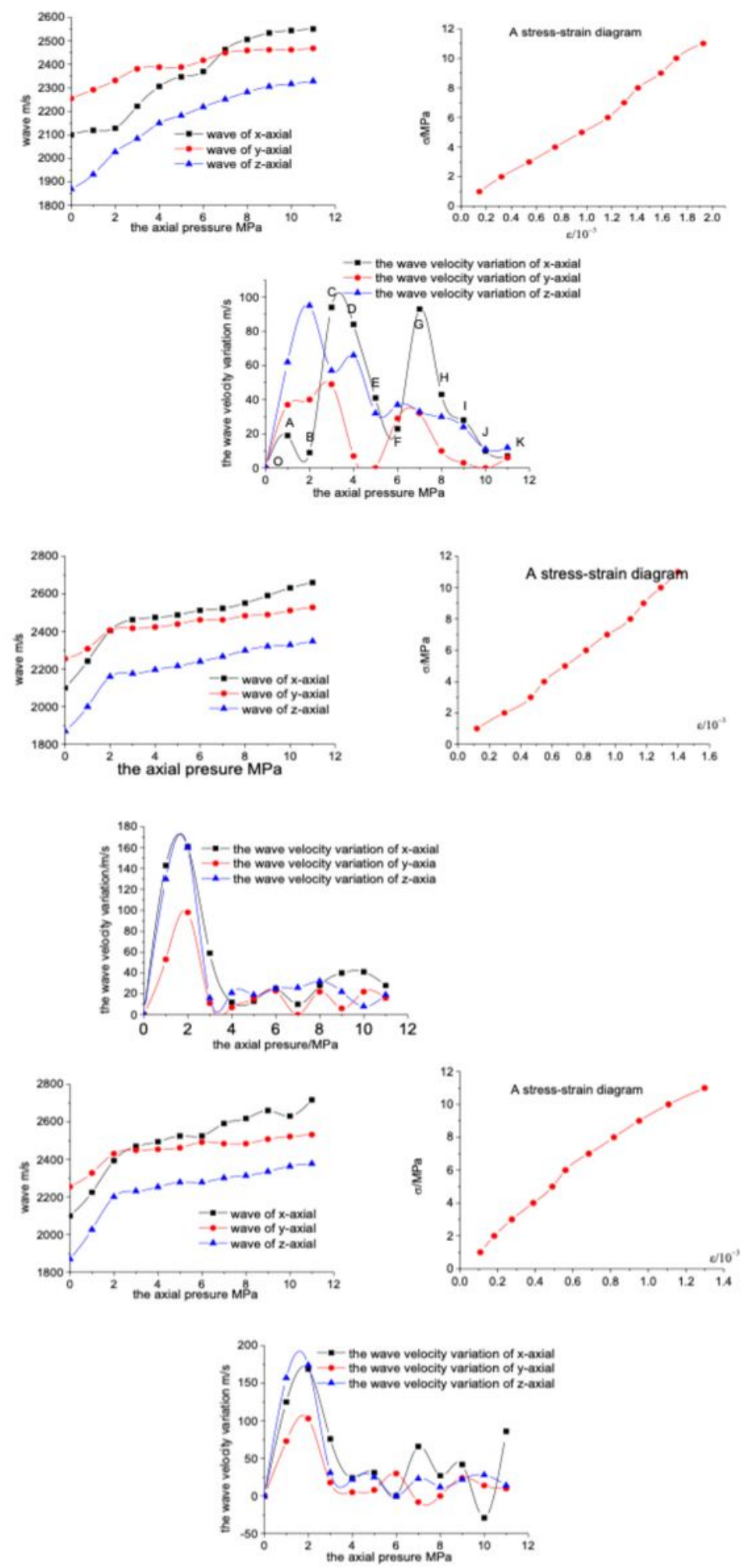

\section{Figure 2}

2-1 Wave velocity, stress-strain curves and wave velocity variations at $X, Y$ and $Z$ axes at $1 M p$ p. 2-2 Wave velocity, stress-strain curves and wave velocity variations at $X, Y$ and $Z$ axes at $1 M P a$. 2-3 Wave velocity, stress-strain curves and wave velocity variation at $X, Y$ and $Z$ axes at the confining of $1 \mathrm{MPa}$ 

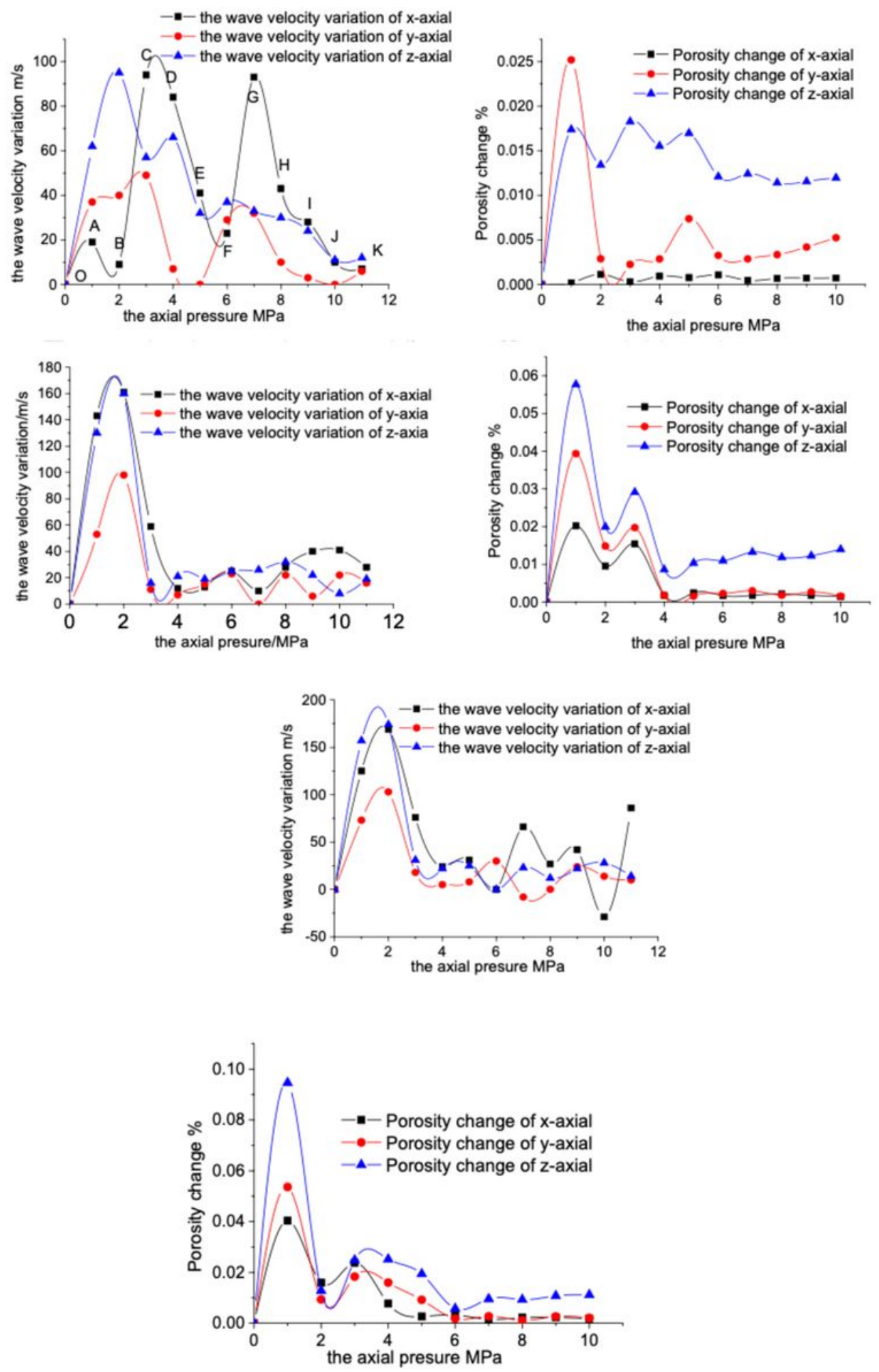

\section{Figure 3}

3-1 Wave velocity change and pore change at the confining pressure of $1 \mathrm{MPa}$. 3-2 Wave velocity change and pore change at the confining pressure of $3 \mathrm{MPa}$. 3-3 Wave velocity change and pore change at the confining pressure of $5 \mathrm{MPa}$ 